\title{
Development of Deterioration Model of Potable Water Distribution System Considering the Material Properties
}

\author{
Miyun Park ${ }^{1}$, Hyundong Lee ${ }^{2,3 *}$ and ByungChoon Sho ${ }^{1}$ \\ ${ }^{1} 6$ F Pureunsol Bldg, 6, Maeheon-ro 16-gil, Seocho-gu, Seoul \\ \{mskong, hdlee,hcshin\}@kict.re.kr, momo6238@hanmail.net \\ ${ }^{2}$ Korea Institute of Civil Engineering and Building Technology, Environment and \\ Plant Engineering Research Institute, 283, Goyang-dae-ro, Ilsanseo-gu, Goyang- \\ si, Gyeonggi-do,Republic of Korea \\ ${ }^{3}$ University of Science and Technology, Construction and Environment \\ Engineering.217, Gajeong-ro, Yuseong-gu,Daejeon,Republic of Koreal \\ *hdlee@kict.re.kr \\ Tel: +82-31-910-0297
}

\begin{abstract}
Water and wastewater facilities of Korea also have been continuously increased with the rapid development of urbanization. Especially in the 80's and 90's, many water pipes had been installed and the useful life of them goes beyond more than 40 years old. These facilities will cause the simultaneous increase of the replacement time and will result of a large of national financial burden on government and society. For this reason, to build the appropriate and reasonable budget investment strategy, the determination of introduction of asset management system about water treatment and wastewater facilities is absolutely needed. Thus, in this study, a certain pilot area for analysis of safety/ technical diagnosis data was selected, methodology of developing aging model for water pipe was studied, and environmental characteristic, and aging tendency was applied for developing of deter model. Through this process, the correlation between the two diagnostics, environmental characteristics was compared and the prediction deterioration model according to material properties was developed. It will be based on the long-term national plan for infrastructure asset management and it will be utilized a very important part of investment decision making for infrastructure.
\end{abstract}

Keywords: Asset management, , Deterioration Model, Regression analysis, Condition evaluation

\section{Introduction}

The water and sewage system in Korea has continuously expanded as the city developed. In particular, a lot of pipe network has been installed in 80s and 90s with the population concentrated in the cities, and the life of these installations reach as much as 40 50 years. Consequently continuing replacement of worn-out pipes has occurred; the budget for it also occupies enormous size. Since we looked at the point of view of only installation (not considering maintenance step) which were decision making method of development era, it brought the absence of facility management point of view for maintenance and management centered.

Continuously and simultaneously increasing the replacement time of worn-out pipes becomes a fiscal burden on our country, thus, input timing for appropriate and reasonable

${ }^{*}$ Corresponding Author 
budget and bringing in of water and sewage asset management system of determined the expense scale was urgently needed.

It applies asset management concept for national infrastructure facilities and the current condition of pipe network, predict the long term pipe network deterioration and determine the appropriate time for maintenance and reinforcement.

In particular, the development of regional environmental characteristics and uses characteristic model is more important than comprehensive concept in development of pipe network, based on environmental, construction impact of facilities and current conditions, development of aging facilities model is a necessary course to anticipate future state. For this reason, this study utilized certain pilot area's safety/ technical diagnosis material, studied methodology of developing aging model for water and sewage pipe applied environmental characteristic, and aging tendency. Recently, A study to establish the comprehensive managing process is advancing in Korea and abroad. It applies asset management concept for national infrastructure facilities and the current condition of pipe network, predict the long term pipe network deterioration and determine the appropriate time for maintenance and reinforcement.

The asset management concept of water and sewage pipe network is a process that presented by using a variety of indicators to assess the current state, by the prediction of aging facilities depending on the time period, it allows maintenance timing and prediction of mid, long-term, replacement costs. In particular, the development of regional environmental characteristics and uses characteristic model is more important than comprehensive concept in development of pipe network, based on environmental, construction impact of facilities and current conditions, development of aging facilities model is a necessary course to anticipate future state.

For this reason, this study utilized certain pilot area's safety/ technical diagnosis material, studied methodology of developing aging model for water and sewage pipe applied environmental characteristic, and aging tendency.

\section{The Research of Domestic and International Trends}

\subsection{Study of Oversee Research}

In foreign countries, there are many ongoing studies for state evaluation of pipe facility and development of aging evaluation model, in some countries, safety leveraging nondestructive diagnostic technologies developed to take advantage of the old prediction model, only the result of its own remuneration model applied to the reinforcement, construction site of the pipeline facilities are showing positive results. The representative deterioration evaluation regression model that applied this methodology was in Des Moines waterworks of Iowa state developed care model and EPA developed model.

In the case of developed model in Des Moines water bureau, pipes networks' numbers of used years were predicted by measuring ground condition and corrosion degree. Predicting direct deterioration on pipes is judged to be an impossible model, evaluation about pipe is possible in nondestructive state though.

In addition, EPA model can predict the first damaged year, and additional number of repair by considering various elements such as diameter of pipe, kinds of pipe, water pressure, soil, damage history, but has a problem that cannot estimate condition change over time by current state rather than damaged time.

\subsubsection{The Des Moines Water Works Model:}

$\mathrm{AGE}=65.78+(0.028 \mathrm{xSR})-(6.338 \mathrm{xpH})-(0.049 \mathrm{xORP})$

Here, AGE: the years to the first damage (years)

SR: the saturated soil resistance $(\Omega \cdot \mathrm{cm})$ 
pH: Soil.

ORP: Oxidation reduction potential (Redox Potential, millivolts)

\subsubsection{The Model of EPA (Environmental Protection Agency):}

Regression model, for estimating a number of years to the first damage $\mathrm{NY}=4.13+0.338 \mathrm{D}-0.022 \mathrm{P}-0.265 \mathrm{I}-0.0983 \mathrm{RE}$ S-0.0003LH+13.28T

(the coefficient of determination $\mathrm{R} 2=0.23$ )

Here NY: the years to the first repair after pipe lay (years)

D: Pipe radius (inch)

P: Absolute water pressure within the pipe (lb/inch2)

I: Percentage of the manufacturing area in the pipe laying area (\%)

RES: Percentage of residential area in pipe laying area

LH: Extension of the high corrosive soil pipe (mile)

T: Types of pipe (metal: 1, reinforced concrete: 0 )

Regression model, for estimating the number of repairs after initial breakage Here, $\mathrm{REP}=(0.1721) \cdot(\mathrm{e} 0.7197) \cdot(\mathrm{e} 0.0044) \mathrm{PRD} \cdot(\mathrm{e} 0.0865) \cdot \mathrm{A}(\mathrm{e} 0.0121) \quad \mathrm{DEV}(\mathrm{SL}) 0.014$

(SH) 0.069 (Coefficient of determination R2 $=0.47$ )

Here, REP: Repair number (s)

PRD: Water pressure difference (lb. / inch2)

A: Number of years elapsed from the initial damage (years)

DEV: Developing area ratio of pipe buried in the area $(\%)$

SL: Low corrosive soil surface area of the tube (inch2)

SH: Tube surface area of the highly corrosive soil (inch2)

T: Types of pipe (metal: 1 , reinforced concrete: 0 )

2.1.3. Other Case Studies: In addition to the case that mentioned earlier, various reports and thesis (HUU,2007) suggest regression model that trace the aging degree by elapsed year as well as calculating least damaged year to evaluate current pipe network status, and anticipate deterioration consequence of usable year. This suggests a variety of forms utilizing the prediction method, etc.,, such as Markov chain, Fuzzy method, Artificial Neural network.

Also, in Japan, they evaluated integrity of pipe facility through direct/indirect diagnosis suggested in research report "Diagnostic pipeline facilities".

It has shown a similar pattern of domestic direct/indirect pipe state evaluation that evaluates usability by identifying the current status. But there is no case that suggests methodology can predict deterioration using existing state evaluation material (measurement, diagnosis) even in the presented various research. Utilize materials that are presented through real diagnosis it seems to require accurate and reliable development model that combines the characteristics of the area.

\subsection{Domestic Case Studies}

Researches on development of aging pipe network evaluation technology in the country are decision System for improved water pipes (hyeondong Lee, 1995), developing 
predictive models of water supply pipeline corrosion and aging (Korea Institute of Construction Technology, 2002) energy-saving building technology for the development of safety diagnosis and assessment of the state within the old water line (Korea Institute of Construction Technology, 2002), Optimal Management of Water Distribution system development (Korea Institute of Construction Technology, 2002), Constant replaces two priorities through the development pipeline condition assessment techniques and the like (Korea Water Resources Corporation, 2004).

In the case of "developing decision making systems for the improvement of the water pipe", there is a limit of application of the actual applying due to the inadequacy of the actual measurement data,

Also it is focused on the aging evaluation applied to regional characteristics less applicability in various fields. In addition, deterioration evaluation methods are presented in "development of predictive aging model and corrosion of water supply." However, applying in a manner that could contain a subjective evaluation during visual inspection would be hard.

"Development of a safe diagnostic technique for the evaluation and diagnosis of the state of energy-saving building in the old water supply pipe" is to assess the state of corrosion and aging of the water supply pipes in the building, and develop a method to be applied to improving construction. However, current maintenance system that rehabilitation and replacement are applied to does not match with the situation where the problem rather than repairing, reinforce the concept of the supply occurs due to the aging of the pipe's characteristic.

"Development of optimal water pipe network management system" applied SCADA (Supervisory-Control and Data Acquisition) for maintenance and optimized facility operation of water pipe's network. Through this, it was designed to manage water flow rate, and leakage amount analysis. This leakage information was occurred by cracks and damage due to impact generated on initial construction process than by the case of deterioration of water pipe. It seems to have limitation to decide administrative status for present water pipe network utilize related material.

Especially, in "development of priority decision making for water pipe state evaluation", field survey and pre-developed deterioration evaluation system about steel pipe and cast iron pipe that are mainly used in wide water work system managed by $\mathrm{K}$ water were verified. In addition, rehabilitated pipe, epoxy steel pipe, stainless pipe and PEP that were buried in various small diameter pipe types were presented.

Deterioration of steel pipe

$=1.50+(0.297 \cdot$ Type ofpipe $)-(0.184 \cdot$ pipediameter $)-(0.203 \cdot$ inner sheath $)-(0.190 \cdot$ install year $)-(0.398 \cdot$ buried depth $)+(0.209 \cdot$ soil kind $)-(0.294 \cdot$ streets around $)-(0.0379 \cdot$ electrical method $)+(0.0486 \cdot$ leakage, damage report $)$

(K-water, 2004)

Deterioration of cast iron

$=.758-(0.153 \cdot$ dia_pipe $)+(0.329 \cdot$ inner sheath $)-(0.109 \cdot$ install year $)+(0.130 \cdot$ buried depth $)-(0.0929 \cdot$ soil kind $)+(0.0020 \cdot$ streets around $)-(0.0091 \cdot$ leakage, damage report $)$

(K-water, 2004) (e) 


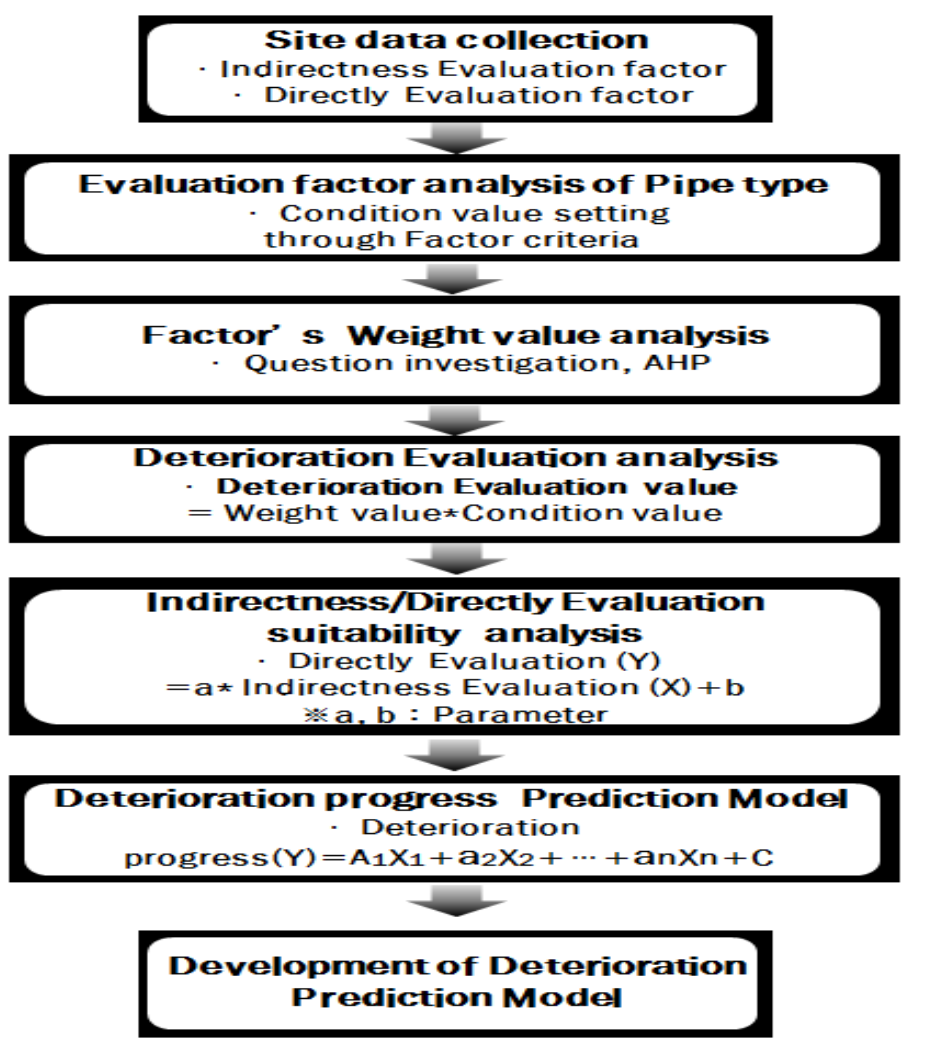

Figure 1. Process of KWI'S Deterioration Model

\section{Condition Assessment Status and Problem Analysis for Water Pipes}

\subsection{Study of Diagnostic Methods by the Target Facility and Characterization}

Diagnosis of water pipes can be divided into safety inspection and technology inspection. Water mains and water pipes are the target in safety inspection. (Korea Infrastructure Safety\& Technology Corporation, 2011) In the case of technology inspection, it is divided into wide area waterworks system and local water service. Targets are water main, water pipe for wide area waterworks system, water pipe, drain pipe, and water supply are for local waterworks system. In addition, safety inspection diagnosed utilized the way that suggested in detailed instruction handbook of safety check and precise safety diagnosis. Water main, water pipe diagnosis guide is used in wide area waterworks system, water pipe network diagnosis manual is used in local waterworks system in Technology inspection. (See Table1)

Facilities state evaluation methods are classified by diagnostic methods, maintenance, and reinforcement concept from each diagnosis result should be applied differently. For grade $\mathrm{C}$ facilities $(2.5 \leq$ condition index $\leq 3.5)$, they were presented after condition assessment in a special law on the safety of the facilities, to carry out maintenance and to reinforce in safety inspection. Table 2, reference.

On the other hand, in the case of technology diagnosis, it is required to implement the expert technical diagnosis after getting "below average" (excellent, good, normal, bad, serious: the case of the 5-stage evaluation), from general technology diagnosis. Indirect and direct evaluation methods also will be used. After Indirect evaluation that can judge the approximate state of the facilities to evaluation method by using pre-information (Types of pipe on pipe network)

After performing the indirect assessment which the evaluation method utilizes the prior information (the tube type, pipe radius, laying year, and etc.,) about the observation by applying the indirect assessment method and direct evaluation method and can judge the 
schematic situation of the facility, it gets to determine the direct evaluation existence and nonexistence according to the evaluation score. Direct evaluation, in the case of deterioration of "careful observation" target facility (equivalent to the indirect evaluation score 4.5 to 6.0 ) by indirect evaluation, it is recommended to judge whether to rehabilitate or replace the pipe to estimate physical condition (measured inner diameter, thickness of the tube, thickness of coating, such as surface corrosion depth) after excavation. (See table 3)

Table 1. Period and Object Pipe for Condition Evaluation Method

\begin{tabular}{|c|c|c|c|}
\hline \multirow[t]{2}{*}{ Classification } & \multicolumn{3}{|c|}{ Water Facility Safety Inspection } \\
\hline & $\begin{array}{l}\text { Periodic } \\
\text { Inspection }\end{array}$ & $\begin{array}{l}\text { Precision } \\
\text { inspection }\end{array}$ & Precision Safety Inspection \\
\hline Related Regulation & \multicolumn{3}{|c|}{$\begin{array}{l}\text { The Special Act on Safety Management of Facilities } \\
\end{array}$} \\
\hline $\begin{array}{l}\text { Inspection Period and } \\
\text { Schedule }\end{array}$ & \multicolumn{3}{|c|}{$\begin{array}{l}\text { - Periodic Inspection : A half one time } \\
\text { - Precision inspection : } 2 \sim 4 \text { year per building levels } \\
1 \text { time Others } \\
1 \text { time per } 1-3 \text { year } \\
\text { - Precision Safety Inspection : } \\
1 \text { time per } 4 \sim 6 \text { year according to levels } \\
\text { ※ The Special Act on Safety Management of Facilities } \\
\text { Enforcement Decree_attached table } 2.1\end{array}$} \\
\hline Facilities & \multicolumn{3}{|c|}{$\begin{array}{l}\text { Intake facility, pipeline facilities } \\
\text { (Intake pipe, Conveyance water pipe, water distribution and } \\
\text { channel tunnel ), } \\
\text { Clean water facilities, pump station, controlled reservoir, } \\
\text { pond, other facilities (periodic inspection only) }\end{array}$} \\
\hline
\end{tabular}

Table 2. Condition Evaluation Criteria in Safety Inspection

\begin{tabular}{c|l}
\hline Level & \multicolumn{1}{c}{ Condition } \\
\hline $\begin{array}{c}\mathrm{A} \\
\text { (Excellence })\end{array}$ & In excellent condition with no problems \\
\hline $\begin{array}{c}\mathrm{B} \\
(\mathrm{Good})\end{array}$ & Minor defects, in need of some maintenance \\
\hline $\begin{array}{c}\mathrm{C} \\
(\text { Normal })\end{array}$ & The main element minor defects, in need of repair \\
\hline $\begin{array}{c}\mathrm{D} \\
(\text { Pool })\end{array}$ & The main element defects, state emergency maintenance needs \\
\hline $\mathrm{E}(\mathrm{Bad})$ & The main element serious defects unusable state \\
\hline
\end{tabular}

Table 3. Condition Evaluation Criteria in Technology Inspection

\begin{tabular}{l|l|l}
\hline Division & Range & Condition \\
\hline \hline \multirow{2}{*}{ Evaluation } & $<0.45$ & replacement/rehabilitation \\
\cline { 2 - 3 } result & $0.45 \sim 0.60$ & Progression \\
\cline { 2 - 3 } & $0.60<$ & good \\
\hline
\end{tabular}


In the safety diagnosis, state evaluation is implemented through steel test, the valve chamber survey, and internal/ external corrosion environment survey (soil resistivity, tube ground potential difference, soil $\mathrm{pH}$, such as moisture content).

It will be determined whether to repair, reinforce of facilities by safety level by state according to the state index calculated here. Through this actual present pipe network can be measured. However, it might result in singular and local amenities unstable after excavation control due to ground disturbance and inconvenience for the residents of the region in such a way that the diagnosis should be diagnosed directly to the network.

In $\mathrm{C}$ rank $(2.5 \leq$ state index $\leq 3.5)$ which presented as maintenance, reinforcement level, it is the status of selecting maintenance and reinforcement and precedes it first. When rating the overall target area for the entire facility is applicable, rather than applying ratings for the tube it is separated by length the details for that grade distribution network facilities that correspond to the level $\mathrm{C}$, cannot be included in the replacement and rehabilitation targets.

On the other hand, for the indirect evaluation of technology diagnosis, direct assessment has to be proceeded to the facility after the evaluation utilizing the prior information. It has an advantage of understanding schematic pipe network state that does not change the state of the current structures rather than safe diagnostic method.

But in this indirect evaluation, it does not evaluate practical pipe network status. Only primary management is possible to manage pipe network before sorted to direct evaluation because there is no method that can apply evaluation result from state evaluation utilize the condition value.

In addition, indirect evaluation method couldn't present a top score of 1.0 in the even in the initial construction time. In other words, initial construction of steel pipe doesn't start at optimal health score of 1.00. It starts at 0.8433 as shown in Figure 2. This applies even if all other conditions to the best state, the condition value to the tube type (Ministry of Environment, 2007) to be expressed by the indirect assessment criteria applied to the differential equation, sensitively to express the aging process according to the time change is set to indicate a significant limitation.

Therefore, in this study, deterioration evaluation model was developed to correct and analyze the relation of aging model between two methods based on technology diagnosis materials and safety diagnosis of pilot area in order to suggest a way to compensate limitations that technological diagnosis has and issues that safety diagnosis has.

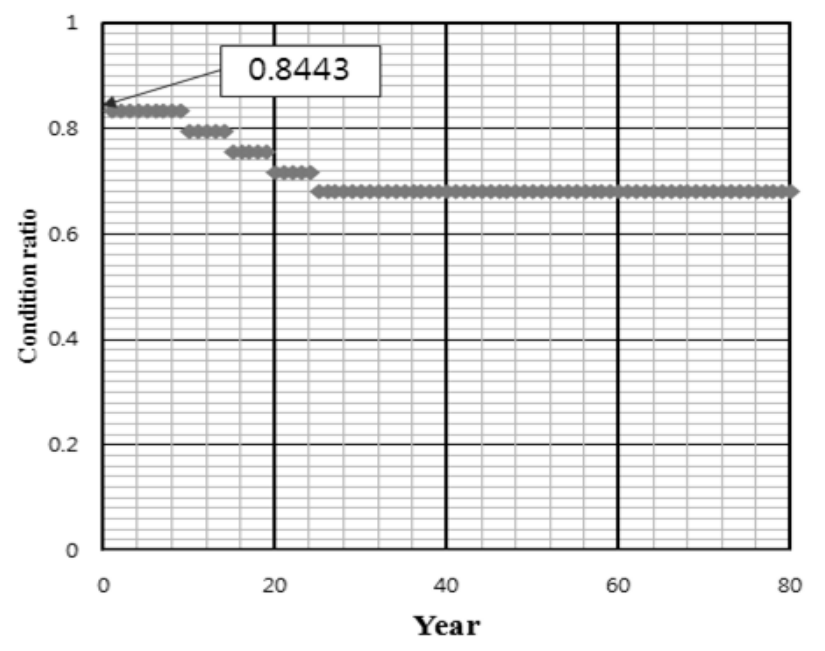

Figure 2. Ratio Evaluation Graph Related to Condition Analysis Method 


\section{Developing Evaluation Model of Water Main Deterioration}

\subsection{Basic Direction of Development of Deterioration Evaluation Model}

Basic direction of the pipe network facilities are follows. First (1) secure each diagnostic data (safety inspection / technical examination) (2) figure out deterioration tendency by analyzing state evaluation index on safety diagnosis that is secured now. (3)Utilize this for analyzing relation between the indirect evaluation results of technology diagnosis and suggest relative safety of diagnostic estimation. (4)Utilize the pipe network characteristic; calculate pipe network state change regression equation after technology diagnosis indirect evaluation.

Then, (5) analyze diagnosis result, draw a correlation (pattern) that was suggested. And finally match (5) the correlation pattern to technology diagnosis regression equation, and suggest final pipe network deterioration model. It suggests a way to apply the criteria presented it in the local public enforcement regulations.

Table 4. Process of Development Deterioration Model

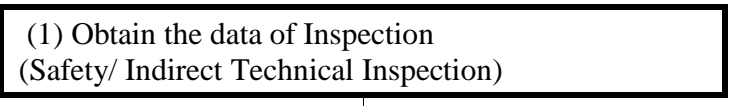

(2) Confirm the trend of Deterioration Slope

(3) Develop Relative Condition Curve Based Safety

Inspection Regression Curve

$$
\begin{aligned}
& \text { (4) Appear Regression Curve based on Indirect } \\
& \text { Inspection } \\
& \begin{array}{l}
\text { (5) Conduct trend analysis of the correlation between } \\
\text { Relative Condition Curve and Indirect Inspection }
\end{array} \\
& \hline
\end{aligned}
$$

(6) Applicability and the proposal of the Deterioration model to Pipe network

\subsection{Result Analysis of State Evaluation of Safety Diagnosis Material}

Safety diagnosis of the distribution network was conducted to evaluate the state separated by A-Line and B-Line, safety information and diagnostic results for the pipe are as follows: Table 5, Table 6 .

For A line, it is a steel pipe, diameter $1650 \mathrm{~mm}$, water main installed in 1999, For Bline, same kinds of pipe, diameter $600 \mathrm{~mm}$, installed in 1991. A line has been used for 12years, and B line has been used for 20years (safety audit happened in 2011). They buried under the street and open area. X-axis lapse of years, Table of Y-axis condition index 5 represents the state index of a graph can be displayed as Figure 3.

The result of diagnosis shows that both A, B line installed in same cycle except few cycles and they were found in good condition.

Utilizing suggested state evaluation data, set initial state index to 5 (the best optimized state), so it can derive the formula (f), (g) identifying aging tendency. The reliability of data was highly calculated at the regression equation of the exponential form in the case of the equation ( $\mathrm{f}$ ) and (g) than the linear type or polynomial expression. And moreover this coefficient of determination was highly suggested $(\mathrm{R} 2=0.894)$

This estimation of deterioration was drawn up from the base of safety diagnosis material. The area's environmental characteristic and external elements (soil, external load 
conditions, degree of internal corrosion, etc.,) were considered to be utilized when it predicts deterioration.

Table 5. Condition Evaluation Through Safety Inspection (A-Line) I

\begin{tabular}{c|c|c|c|c}
\hline Section & Distance & $\begin{array}{l}\text { Top of the } \\
\text { structure }\end{array}$ & Condition & Condition Ratio \\
\hline \hline a1 & 825 & Road & b & 3.64 \\
\hline a2 & 9 & Non-Road & b & 3.6 \\
\hline a3 & 186 & Road & b & 3.6 \\
\hline a4 & 391 & Non-Road & b & 3.6 \\
\hline$\cdot$ & $\cdot$ & $\cdot$ & $\cdot$ & $\cdot$ \\
$\cdot$ & $\cdot$ & $\cdot$ & $\cdot$ & $\cdot$ \\
\hline & $\cdot$ & $\cdot$ & $\cdot$ & $\cdot$ \\
\hline a21 & 13 & Non-Road & b & 3.6 \\
\hline a22 & 660 & Non-Road & b & 3.6 \\
\hline a23 & 74 & Non-Road & b & 3.6 \\
\hline a24 & 437 & Non-Road & b & 3.6 \\
\hline
\end{tabular}

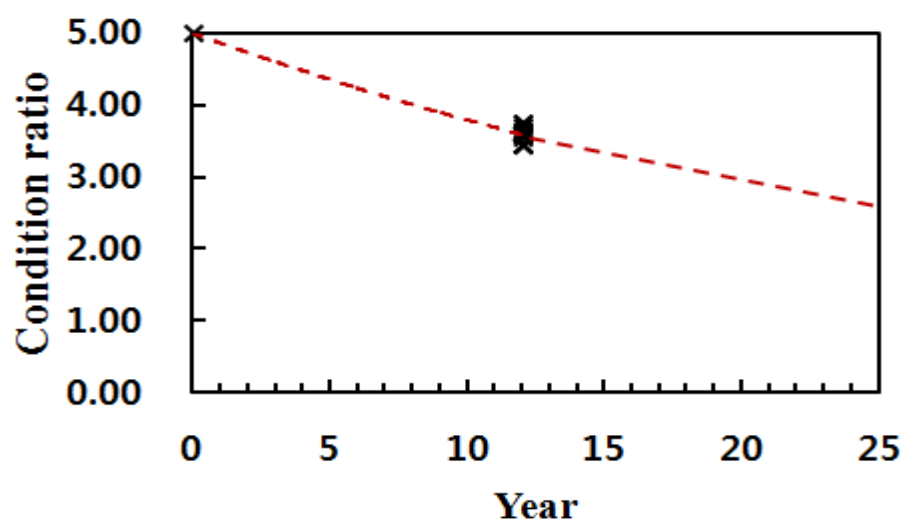

Figure 3. Deterioration Trend in Safety Inspection (A-Line)

$\mathrm{Y}=5 \mathrm{e}-0.028 \mathrm{X}(\mathrm{R} 2=0.894)$

Here, Y : score, $\mathrm{X}$ : year

Table 6. Condition Evaluation Through Safety Inspection (B-Line)

\begin{tabular}{c|c|c|c|c}
\hline Section & Distance & $\begin{array}{c}\text { Top of the } \\
\text { structure }\end{array}$ & Condition & Condition Ratio \\
\hline \hline b1 & 173 & Road & b & 3.75 \\
\hline b2 & 47 & Non-Road & b & 3.6 \\
\hline b3 & 102 & Road & b & 3.6 \\
\hline b4 & 221 & Non-Road & b & 3.75 \\
\hline$\cdot$ & $\cdot$ & $\cdot$ & $\cdot$ & $\cdot$ \\
$\cdot$ & $\cdot$ & $\cdot$ & $\cdot$ & $\cdot$ \\
\hline & $\cdot$ & $\cdot$ & $\cdot$ & $\cdot$ \\
\hline b13 & 270 & Non-Road & b & 3.66 \\
\hline b14 & 931 & Road & b & 3.6 \\
\hline b15 & 401 & Non-Road & c & 3.09 \\
\hline b16 & 232 & Road & b & 3.6 \\
\hline
\end{tabular}


The unusual point of regression equation on diameter D 1650 and D600, D600 which has smaller diameter shows slower deterioration level. D1650 was installed in 2002, its changes of the condition grade were slow and good in the safety test due to seldom used after operation.

$\mathrm{Y}=5 \mathrm{e}-0.018 \mathrm{X}(\mathrm{R} 2=0.5909)$

Here, Y : score, X : year

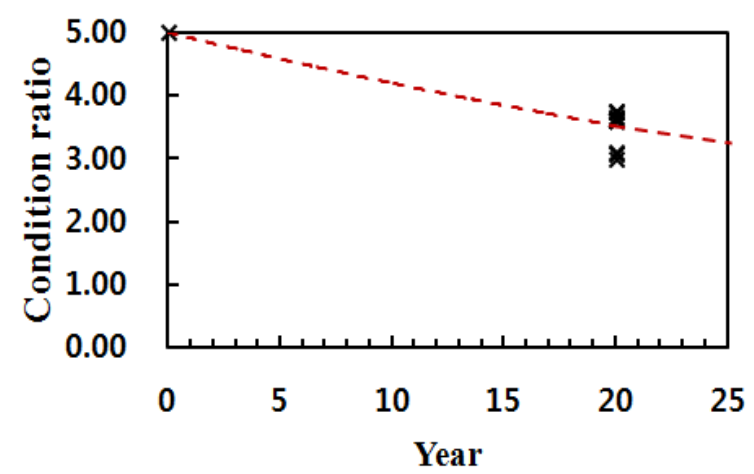

Figure 4. Deterioration Trend in Safety Inspection (B-Line)

\subsection{The State Evaluation Result of Technology Diagnosis Material}

For technical diagnosis, based on the basis of data held by the executive agencies and history data (2013) from the technical diagnostic report, indirect evaluation (Ministry of Environment, 2007) was conducted to evaluate deterioration.

The score in the result of performance later years was performed the on pipe type, indirect assessment calculated with $0.7297 \sim 0.8872$ from the safety test. The evaluation result was exposed to be excellent.

This is the similar results to safety diagnosis result. However, the starting point, 0.8443 initial deterioration is the result by restriction of condition value about pipe type that suggested as a problem of technology diagnosis earlier. It was differ from safety diagnosis that assume initial state as the best state.

Table 7. Condition Evaluation Through Indirect Evaluation (D1650)

\begin{tabular}{c|c|c|c|c}
\hline Diameter & Type & Install & $\begin{array}{c}\text { Top of the } \\
\text { structure }\end{array}$ & Condition Ratio \\
\hline \hline 1650 & SP & 1999 & Streets & 0.8347 \\
\hline 1650 & SP & 1999 & Streets & 0.8727 \\
\hline 1650 & SP & 1999 & Road & 0.7297 \\
\hline 1650 & SP & 1999 & Road & 0.8057 \\
\hline$\cdot$ & $\cdot$ & $\cdot$ & $\cdot$ & $\cdot$ \\
$\cdot$ & $\cdot$ & $\cdot$ & $\cdot$ & $\cdot$ \\
$\cdot \cdot$ & $\cdot$ & $\cdot$ & $\cdot$ & $\cdot$ \\
\hline 1650 & SP & 1999 & Road & 0.7297 \\
\hline 1650 & SP & 1999 & Road & 0.8057 \\
\hline 1650 & SP & 1999 & Road & 0.8057 \\
\hline 1650 & SP & 1999 & Road & 0.7297 \\
\hline
\end{tabular}

Table 7, and Figure 5, express deterioration tendency of 1650mm and steel pipe of target pilot area. 


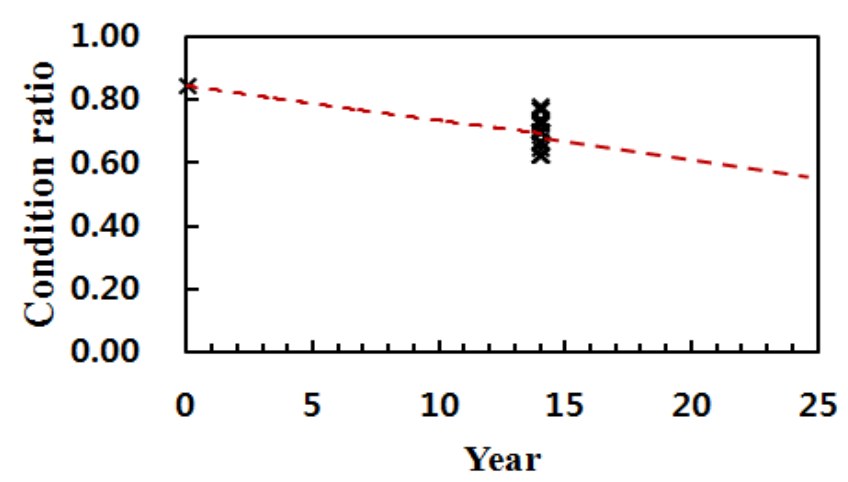

Figure 5. Deterioration Trend in Indirect Evaluation (D1650)

$\mathrm{Y}=0.8443 \mathrm{e}-0.004 \mathrm{X}(\mathrm{R} 2=0.834)$

Here, $\mathrm{Y}$ : score, $\mathrm{X}$ : year

Table 8. Condition Evaluation Through Indirect Evaluation (D600)

\begin{tabular}{l|l|l|l|c}
\hline Diameter & Type & Install & Top of the structure & $\begin{array}{c}\text { Condition } \\
\text { Ratio }\end{array}$ \\
\hline \hline 600 & SP & 1991 & Road & 0.6776 \\
\hline 600 & SP & 1991 & Road & 0.6161 \\
\hline 600 & SP & 1991 & Road & 0.7301 \\
\hline$\cdot$ & $\cdot$ & $\cdot$ & $\cdot$ & $\cdot$ \\
$\cdot$ & $\cdot$ & $\cdot$ & $\cdot$ & $\cdot$ \\
\hline 600 & $\cdot$ & $\cdot$ & $\cdot$ & $\cdot$ \\
\hline 600 & SP & 1991 & Road & 0.6921 \\
\hline 600 & SP & 1991 & Road & 0.6921 \\
\hline & SP & 1991 & Road & 0.6921 \\
\hline
\end{tabular}

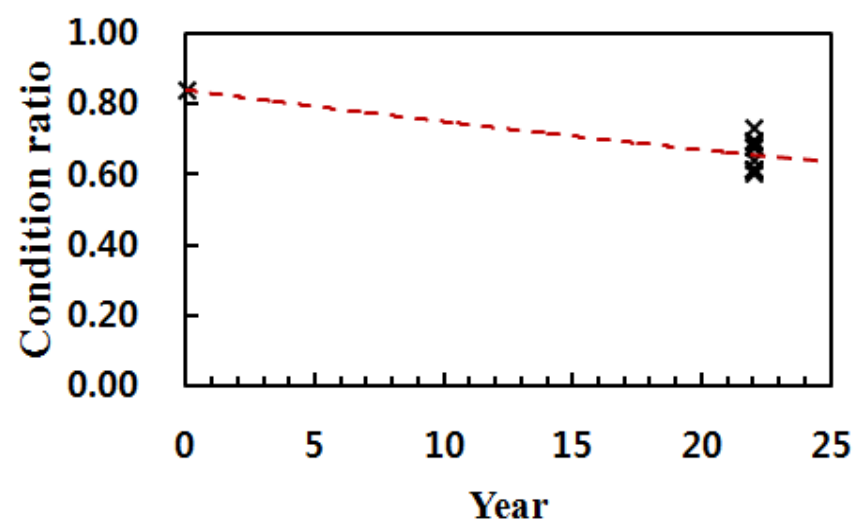

Figure 6. Deterioration Trend in Indirect Evaluation (D600)

Table 8, and Figue 6, express deterioration tendency analyzing SP(D600) of same area. $\mathrm{Y}=0.8383 \mathrm{e}-0.011 \mathrm{X}(\mathrm{R} 2=0.4705)$

Here, $\mathrm{Y}$ : score, $\mathrm{X}$ : year

Indirect evaluation in technology diagnosis standard mainly considered leakage and happening of complaint. It gives weighted value according to condition value through the 
basic information on pipe network about diameter, pipe type, buried year, condition of the soil etc., There is a weak part that doesn't seem analyze present pipe state practically compares to direct diagnosis. However, it is decided to consider enough first the physical condition that it reflects the characteristic or characteristic to be usefully applied in the asset management concept which it presents the optimum administration condition of the facility property.

\subsection{Development Dterioration Model that Reflect Pipe Network Characteristic Through Comparison Analysis of Safety/ Technology Diagnosis}

Calculating the results of the analysis before using the safety diagnostic state index in order to supplement the benefits of indirect evaluation method of technical diagnostics to the original (non-destructive evaluation) and the limit (not the state of the direct field is applied) old age aging trend to technical diagnosis results and are matched can complement the limits of indirect evaluation method of technical diagnostics also tried presenting a predictive model.

The safety test deterioration tendency and technology diagnosis indirect evaluation deterioration tendency were calculated according to the expiration year number change for this purpose. The correlation about this was analyzed. First, it is organized in order to convert to the absoluteness unit standard which is used in the technical diagnosis and compare by the same standard. As shown in graph, and are also different from the initial aging indicators it may be found to be expressed also very different from the tendency of each of the slope.

In order to improve these problems, diagnostic initial value is adjusted to be the same and so the impact on the results of the diagnostic technique, each of which has adjustment and methodology are necessary. First, analyze the gap between two graphs for this and reorganize residuals of the derived value from the gap analysis in regression equation and add to indirect evaluation index and push conversion ahead to indirect evaluation result value. The result was carried to the correlation analysis and direct evaluation result value. Table 9 presents these process according to the procedure.

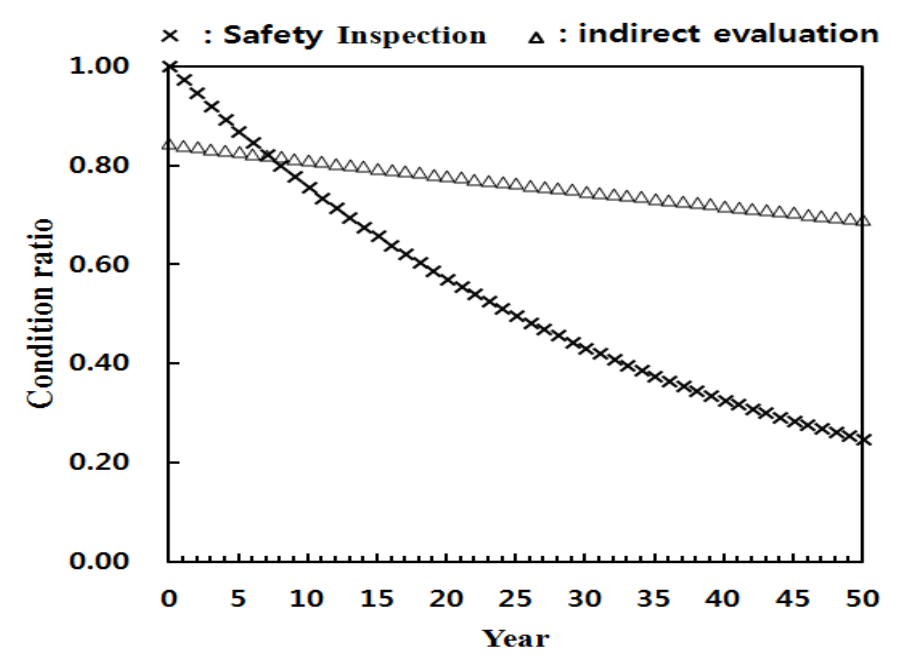

Figure 7. Residual Analysis (D1650)

$\mathrm{Y}=0.0002 \mathrm{X} 2-0.0214 \mathrm{X}+0.1437(\mathrm{R} 2=0.998)$

Here, Y : State evaluation score, $\mathrm{X}:$ (year) 


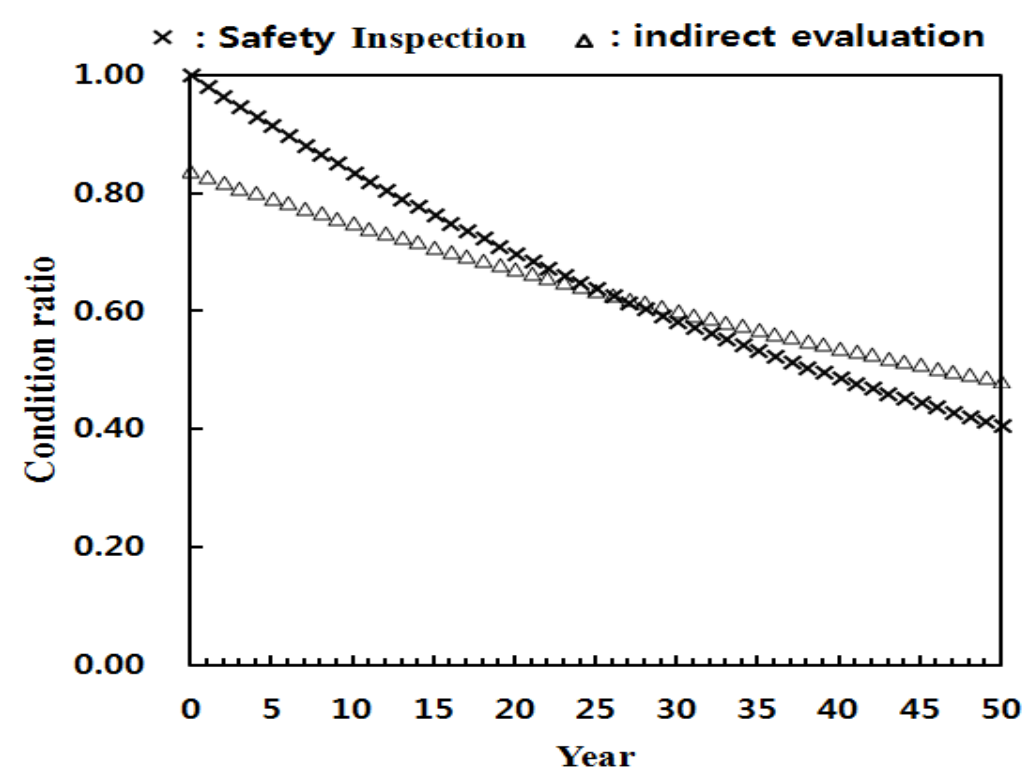

Figure 8. Residual Analysis (D 600)

$\mathrm{Y}=0.00002 \mathrm{X} 2-0.0027 \mathrm{X}+0.064(\mathrm{R} 2=0.999)$

Here, $\mathrm{Y}$ : state evaluation score, $\mathrm{X}:$ (year)

Table 9. Deterioration Prediction Through Correlation Analysis and Conversion (D1650)

\begin{tabular}{|c|c|c|c|c|c|}
\hline Year & $S \cdot I$ & $\mathrm{~S} \cdot \mathrm{I} \cdot \mathrm{M}$ & $\mathrm{I} \cdot \mathrm{E}(1)$ & $\mathrm{R} \cdot \mathrm{A}(2)$ & $(1)+(2)$ \\
\hline 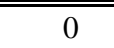 & 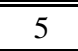 & 1 & 0.84 & 0.14 & 0.99 \\
\hline 1 & 4.86 & 0.97 & 0.84 & 0.12 & 0.96 \\
\hline 2 & 4.73 & 0.95 & 0.84 & 0.1 & 0.94 \\
\hline 3 & 4.6 & 0.92 & 0.83 & 0.08 & 0.92 \\
\hline 4 & 4.47 & 0.89 & 0.83 & 0.06 & 0.89 \\
\hline 5 & 4.35 & 0.87 & 0.83 & 0.04 & 0.87 \\
\hline$\cdot$ & . & . & . & . & . \\
\hline . & . & . & . & . & . \\
\hline . & . & . & . & . & . \\
\hline 45 & 1.42 & 0.28 & 0.71 & -0.42 & -0.41 \\
\hline 46 & 1.38 & 0.28 & 0.7 & -0.42 & 0.28 \\
\hline 47 & 1.34 & 0.27 & 0.7 & -0.42 & 0.28 \\
\hline 48 & 1.3 & 0.26 & 0.7 & -0.42 & 0.27 \\
\hline 49 & 1.27 & 0.25 & 0.69 & -0.42 & 0.27 \\
\hline 50 & 1.23 & 0.25 & 0.69 & -0.43 & 0.26 \\
\hline \multicolumn{3}{|c|}{$\begin{array}{l}\text { S.I : Safety Inspection } \\
\text { S.I.M : Safety Inspection Modify }\end{array}$} & \multicolumn{3}{|c|}{$\begin{array}{l}\mathrm{I} \cdot \mathrm{E}: \text { indirect Evaluation } \\
\mathrm{R} \cdot \mathrm{A}: \text { Residual Analysis }\end{array}$} \\
\hline
\end{tabular}


Table 10. Deterioration Prediction Through Correlation Analysis and Conversion (D600)

\begin{tabular}{c|c|c|c|c|c}
\hline Year & S·I & S·I·M & I·E (1) & R·A (2) & $(1)+(2)$ \\
\hline \hline 0 & 5 & 1 & 0.93 & 0.064 & 1 \\
\hline 1 & 4.91 & 0.98 & 0.91 & 0.061 & 0.98 \\
\hline 2 & 4.82 & 0.96 & 0.9 & 0.058 & 0.96 \\
\hline 3 & 4.73 & 0.95 & 0.89 & 0.056 & 0.95 \\
\hline 4 & 4.65 & 0.93 & 0.87 & 0.054 & 0.93 \\
\hline 5 & 4.56 & 0.91 & 0.86 & 0.87 & 0.87 \\
\hline$\cdot$ & $\cdot$ & $\cdot$ & $\cdot$ & $\cdot$ & $\cdot$ \\
$\cdot$ & $\cdot$ & $\cdot$ & $\cdot$ & $\cdot$ & $\cdot$ \\
$\cdot$ & $\cdot$ & $\cdot$ & $\cdot$ & $\cdot$ & $\cdot$ \\
\hline 45 & 2.22 & 0.44 & 0.46 & -0.017 & 0.44 \\
\hline 46 & 2.18 & 0.44 & 0.45 & -0.018 & 0.43 \\
\hline 47 & 2.15 & 0.43 & 0.44 & -0.019 & 0.42 \\
\hline 48 & 2.11 & 0.42 & 0.43 & -0.02 & 0.42 \\
\hline 49 & 2.07 & 0.41 & 0.43 & -0.02 & 0.41 \\
\hline 50 & 2.03 & 0.41 & 0.42 & -0.021 & 0.4 \\
\hline
\end{tabular}

Presented formula $(\mathrm{J}),(\mathrm{K})$ applied to diameter $1650 \mathrm{~mm}$ and $600 \mathrm{~mm}$ steel pipe. When this is based on the criteria that have been shown to Table 12, 13 in those corresponding to, 0.6 which is the reference of a good state is about 18years. Exchange, and rehabilitation state 0.45 is analyzed about 29 years. And equation corresponding to the steel pipe $600 \mathrm{~mm}$ presented by performing the same method is excellent condition 28years. Replacement and rehabilitation were analyzed to be older than 40years.

Therefore, or prediction development methodology about suggested pipe network deterioration judged to make up a limitation of technology diagnosis partly. When the safety diagnosis data is secured over the period in the future, reliable prediction of deterioration model seems to be possible.

(1) D1650 aging pipe model equation

$Y=\left(0.8443 e^{-0.004 X}\right)+\left(0.0002 X^{2}-0.0214 X+0.1437\right)$

Here, $\mathrm{Y}$ : state condition score, $\mathrm{X}$ : (year)

(2) $\mathrm{D} 600$ aging pipe model equation

$Y=\left(0.8383 e^{-0.0112)}\right)+\left(0.00002 X^{2}-0.0027 X+0.064\right)(\mathrm{m})$

Here, $\mathrm{Y}$ : state condition score, $\mathrm{X}:$ (year)

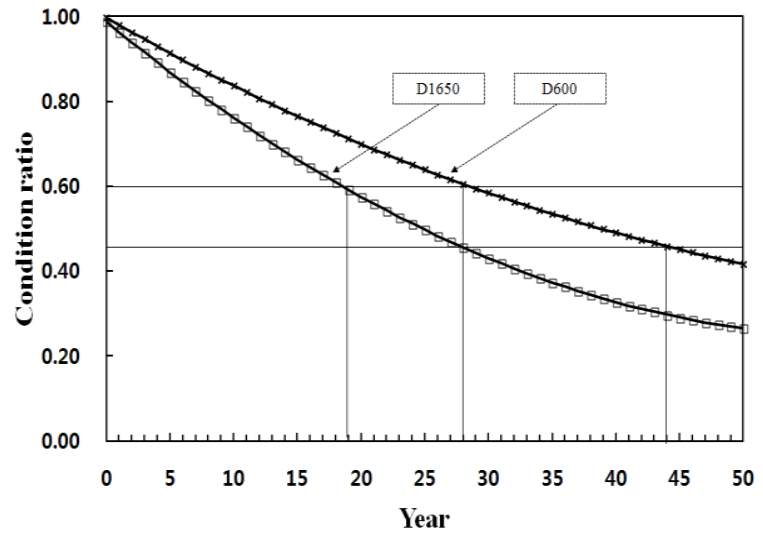

Figure 9. Deterioration Predict Model 


\subsection{Validity and Applicability of Presented Aging Models Review}

4.4.1. Validity Review of Aging Model Feasibility: It's about steel pipe in the case of developed aging model, steel pipe from the water and sewage pipe has been defined as $30 y e a r s$ from local public company law enforcement regulation. Compare this standard to suggested deterioration model under the assumption that the rehabilitation and replacement in 30years shown as Figure 10.

It is presented that local public company law and deterioration model tendency are formed similar in comparison result. For water main, applied suggested deterioration model in the study, showed more conservative tendency. It showed one year difference in rehabilitation and replacement criteria, even if we apply deterioration model of water main in this area the developed model from this study it is judged to be able to ensure the legal validity based on the local public company law.

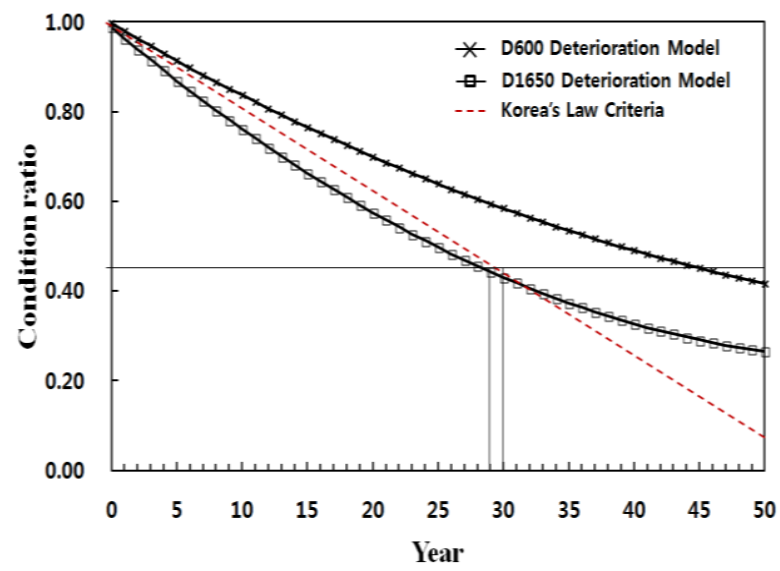

Figure 10. Predictive Model Validation

4.4.2. Reviewing Expansion of Applying Deterioration Model.: The scheme was presented to apply an aging model when field diagnostic data was incomplete in order to maximize application of aging model suggested in the study. It presents a method that can be applied to various pipe types incorporate with pre-developed aging model and derives pipe type ratio by utilizing technology diagnosis indirect evaluation (Ministry of Environment, 2007).

The ratio of pipe type is calculated state index by changing the change of the buried year and pipe type of condition value (STS: 1, DCIP: 0.75, SP: 0.5, PVC, CIP: 0) and apply main condition value presented in a particular target area (internal, external coating conditions, the connecting method (see Table 11)).

It is represented as shown in Figure 11, by graph. This shows the same tendency as Figure 2, move to the axis regularly by change in the condition value of the buried year and pipe type. It calculates the percentage by pipe type on the basis of the relationship between those. The aging model can be presented by pipe types by utilizing the ratio according to suggested pipe type. It presents analysis of aging tendency of safety diagnosis/technology diagnosis equal to when it first developed aging model. For presented equation, it presents aging model of each pipe type by applying regular pipe type ratio analyzed above aging tendency of the steel pipe which is secured before. 


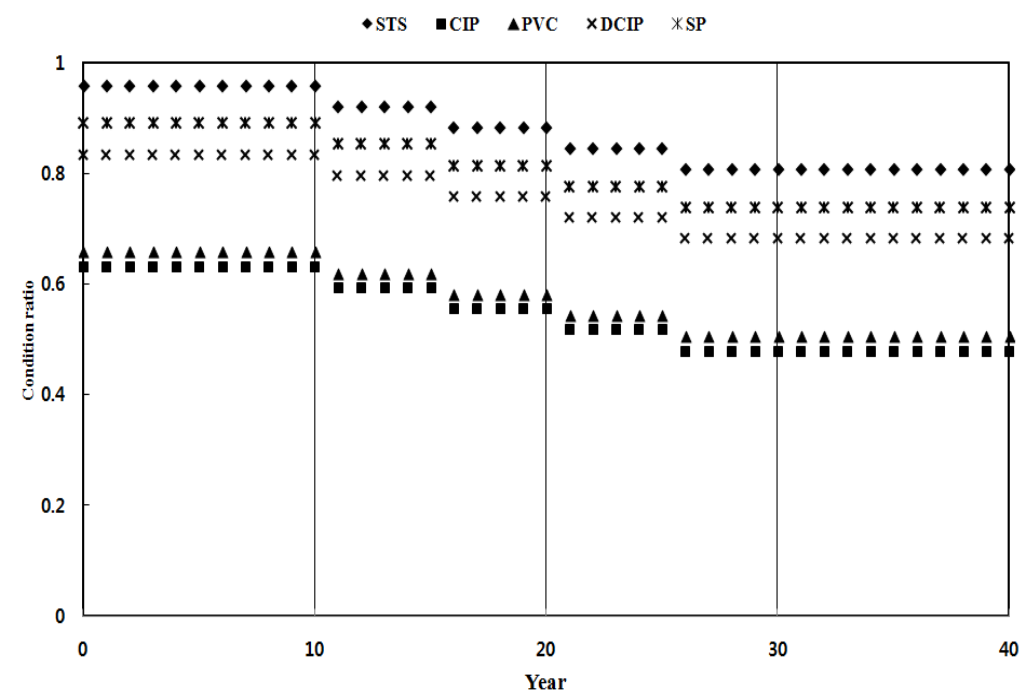

Figure 11. Ratio Analysis of Pipe Type

Table 11. Pipe Type Ratio Analysis Through Technology Inspection

\begin{tabular}{c|c||c|c|c|c|c}
\hline \multicolumn{2}{c||}{ Type } & STS & DCIP & SP & PVC & CIP \\
\hline \hline \multirow{2}{*}{$\begin{array}{c}\text { Condition } \\
\text { Value }\end{array}$} & $\begin{array}{c}\text { Inner } \\
\text { sheath }\end{array}$ & 1 & 0.5 & 1 & 0 & 0 \\
\cline { 2 - 6 } & $\begin{array}{c}\text { Outer } \\
\text { sheath }\end{array}$ & 1 & 1 & 0.75 & 0 & 0 \\
\cline { 2 - 7 } & $\begin{array}{c}\text { Connection } \\
\text { type }\end{array}$ & 1 & 0.5 & 1 & 0.5 & 0.5 \\
\hline \hline \multicolumn{2}{c|}{ Pipe type ratio } & 0.96 & 1.067 & 1 & 1.365 & 1.407 \\
\hline
\end{tabular}

For this aging model, some part of aging tendency is applied and showed by pipe type of technology diagnosis indirect evaluation tendency. It modified and supplemented by utilizing safety diagnostic data assumed value of initial state that was presented early. In addition, the analysis derived aging trends and relationships between pipe type. It presented aging model that can be applied for pipe type (sSTS, DCIP, SP, PVC, CIP) which were mainly used in the pipe network in the country.

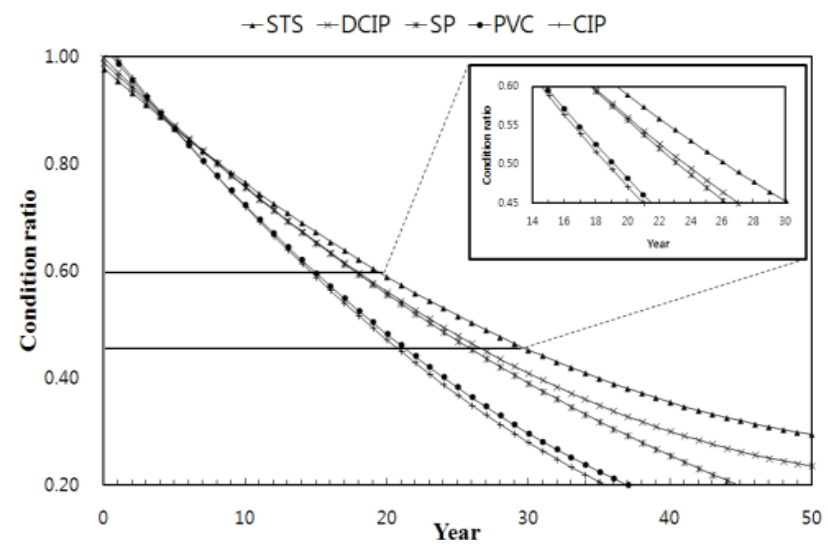

Figure 12. Applicability of Deterioration Predict Model 


\section{Conclusion}

This study is about deterioration prediction model to apply asset management concept for pipe network in national infrastructure. For this, different diagnostic method characteristics of domestic and international case studies were examined. As a result, deterioration prediction model for pipe network from domestic and international studies were suggested but there were no case to organize a concept or present a clear criteria for reasonable consideration of the basic data. It is displayed characteristics and problems that appear in each method by analyzing two diagnosis methods.(Safety diagnosis/ Technology diagnosis)

Based on this, figure out state index tendency according to the number of years and present a result that evaluates site state directly in safety diagnosis data. And after technology diagnosis indirect evaluation by utilizing the data of the area, it drew deterioration tendency same to safety diagnosis. Moreover, with respect to the proposed aging models, it was reviewed by reference and comparative analysis presented in local public enforcement regulations about the legal validity.

It presented applicability to take advantage of the development of aging models to develop aging models for various pipe type used for domestic distribution network.

For the model presented here is used to complement limitation and problems of technology diagnosis indirect evaluation using safety diagnosis data. It proposed a methodology for aging models development to predict the aging of the facility in a limited diagnostic data.

It is judged to present more accurate and reliable aging model by utilizing accumulated data through planned facility state diagnosis activity in a constant cycle for aging model about presented pipe network. It is determined that can be a cornerstone for applying the concept of asset management for water and sewage pipe network.

\section{Acknowledgments}

This study has been reported using the results calculated through research for the order "Urban infrastructure asset management platform and service model" from 2013 industrial fusion source technology development business.

\section{References}

[1] Ministry of Environment: Water Distribution System Diagnostics Manual, (2007).

[2] Korea Infrastructure Safety and Technology Corporation (KISTEC): Detailed guidance of safety inspection and in-depth safety inspection in Korea, (2011).

[3] H. D. LEE, "Development of decision support system for improving water pipes", (1995).

[4] KICT, Development of Prediction Model of Corrosion Status and Pipe Deterioration in Water Distribution Systems, (2002).

[5] KICT, Development of integrated nondestructive diagnosis technique for the state diagnosis and evaluation of deteriorated service pipe in the building, (2002).

[6] K-water, Prioritizing water Mains Rehabilitation base on the field Evaluation, (2004).

[7] H. D. TRAN, "Investigation of Deterioration model for Storm water pipe systems", Victoria University, (2007).

[8] R. M. Clark, C. L. Stafford and J. A. Goodrich, "Water distribution systems :a spartial and cost evaluation", Journal of Water Resources planning and Management Division, ASCE, vol. 108, no. 3, (1982), pp. 243-256 


\section{Authors}

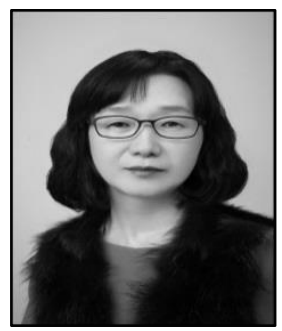

Miyun Park, ACADEMIC BACKGROUND: ,Feb 2007, Hanyang University, Ph.D in Civil Engineering. Aug 2002, Hanyang University, MS in Architectural Engineering. Feb 1999, Hanyang University, Bachelor of Architectural Engineering, PROFESSIONAL EXPERIENCE: Jan 2012 S.H.Tech \& Policy Institute Co., Director of R\&D Center. Jan $2009 \sim$ Dec 2011, SEUNGHWA ENC Co., Director of R\&D Center. Nov 2007 Jan 2009, IAM Cooperation Co., Director of R\&D Center. Apr 2004 $\sim$ Nov 2007, Envico Consultant Co., Assistance Director of Bridge Structural Design Part

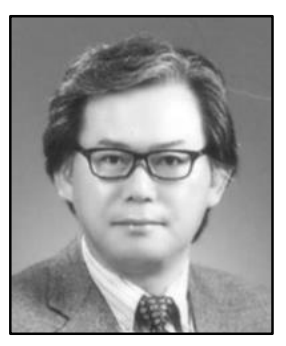

Hyundong Lee, ACADEMIC BACKGROUND: Oct 1993, Kyoto University, Post-Ph.D in Environmental Engineering. Aug 1991, Hanyang University, Ph.D in Civil and Environmental Engineering. Feb 1987, Hanyang University, MS in Civil and Environmental Engineering. PROFESSIONAL EXPERIENCE:

Sep 2007 , Korea University of Science \& Technology, Professor with Department of Construction \& Environment Engineering Dec 2004 Dec 2005, The University of Iowa, Visiting Professor with Department of Civil \& Environmental Engineering

Jul 1987 , Korea Institute of Civil Engineering and Building Technology, Senior Research Fellow, Environment and Plant Engineering Research Institute

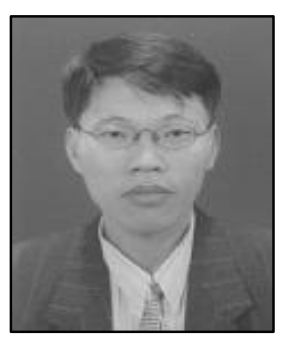

ByungChoon Sho, ACADEMIC BACKGROUND: Feb 2004, Hanyang University, MS in Civil and Engineering. Feb 2004, Hanyang University, BE in Civil and Engineering PROFESSIONAL EXPERIENCE: Jan 2012 , S.H.Tech \& Policy Institute Co.,General Director 